\title{
IMPLEMENTASI USER EXPERIENCE MENGGUNAKAN METODE DESIGN THINKING PADA PROTOTYPE APLIKASI CLEANSTIC
}

\author{
Gusti Karnawan'), Septi Andryana', Ratih Titi Komalasari' ${ }^{3)}$ \\ ${ }^{1,2,3}$ Fakultas Teknologi Komunikasi dan Informatika, Program Studi Informatika, Universitas Nasional \\ ${ }_{1,2,3} \mathrm{Jl}$. Sawo Manila No.16, Jakarta Selatan \\ Email: 'hellogeka@gmail.com, ${ }^{2}$ septi.andryana@civitas.unas.ac.id, ${ }^{3}$ ukhuwahku01@gmail.com
}

\begin{abstract}
The problem of plastics is the biggest contributor to waste, because its unexplained nature results in the effect of too much plastic waste which then becomes one of the reasons for its imbalance in nature. The resulting threats ranging from health, damage to ecosystems and many other things are a problem that exists today. The purpose of this prototype is to educate the public about plastic waste processing and also make it easier for people with this Android-based prototype to sell or donate plastic waste to those in need. The method used in this research is design thinking from the beginning of the design to the end, so as to produce a good user experience. From the evaluation results obtained from testing the prototype using the System Usability Scale (SUS) and User Experience Questionnaire (UEQ) with learnability results of 62.5, usability 82.2, SUS score 78.8 and impression of attractiveness group 2.197, perspicuity 2.275 , efficiency 2.150 , dependability 2.050, stimulation 2.383 , novelty 2,089. The overall test results get good and excellent results.
\end{abstract}

Keywords: Design Thinking, Plastic, Prototype, System Usability Scale, User Experience, User Experience Questionnaire.

\section{Abstrak}

Permasalahan plastik menjadi penyumbang terbesar limbah, karena sifatnya yang sulit teruarai menghasilkan efek terlalu banyaknya limbah plastik yang kemudian menjadi salah satu sebab ketidakseimbangannya alam. Ancaman yang dihasilkan mulai dari kesehatan, rusaknya ekosistem dan banyak hal lainnya merupakan sebuah masalah yang ada saat ini. Tujuan dari prototype ini adalah untuk mengedukasi masyarakat tentang pengolahan sampah plastik dan juga mempermudah masyarakat dengan prototype berbasis android ini dalam menjual ataupun menyumbangkan sampah plastiknya kepada yang membutuhkan. Metode yang digunakan dalam penelitian ini adalah design thinking mulai dari awal perancangan sampai akhir, sehingga menghasilkan tingkat user experience yang baik. Dari hasil evaluasi yang didapat dari pengujian prototype menggunakan System Usability Scale (SUS) dan User Experience Questionnaire (UEQ) dengan hasil learnability 62.5, usability 82.2, SUS score 78.8 serta impresi kelompok attractiveness 2.197, perspicuity 2.275 , efficiency 2.150 , dependability 2.050 , stimulation 2.383 , novelty 2.089 . Keseluruhan hasil pengujian mendapatkan hasil good dan excellent.

Kata Kunci: Design Thinking, Plastik, Prototype, System Usability Scale, User Experience, User Experience Questionnaire.

\section{Pendahuluan}

Perkembangan teknologi yang terus berkembang seiring berjalannya waktu, menuntut kita untuk terus bisa membuat inovasi dalam membuat segala hal yang bersifat tradisional menjadi modern dengan memanfaatkan teknologi yang telah ada. Banyak masalah yang muncul di era serba instan saat ini, penggunaan plastik yang berlimpah menjadi salah satu masalah yang muncul pada zaman sekarang dan hal itu menjadi kerisauan banyak orang. Dampak yang muncul dari penggunaan plastik yang berlebihan dapat mengancam bahkan merusak ekosistem baik di darat, laut maupun udara. Dari sisi kesehatan pun sangat amat mengancam, sumber makanan yang kita makan bisa menjadi berbahayakan akibat tercemarnya sampah-sampah plastik tersebut.

Dari beberapa penelitian sebelumnya yang telah melakukan penelitian mengenai pengimplementasian user experience. Penelitian yang dilakukan oleh Sabika Amalina (2017) melakukan testing pada aplikasinya menggunakan pengujian lapangan[1]. Penelitian yang dilakukan oleh Aria Ar Razi (2018) melakukan testing pada aplikasinya menggunakan pengujian ujicoba prototyping dan kuesioner [2]. Kemudian penelitiaan yang dilakukan oleh Lutfi Fanani (2018) melakukan testing pada aplikasinya dengan menggunakan blackbox [3]. Selanjutnya penelitian yang dilakukan Yulius Firantoko (2019) melakukan testing pada aplikasinya menggunakan pengujian metode Heuristic Evaluation[4]. 
Melihat acuan dari penelitian-penelitian sebelumnya yang telah dilakukan oleh beberapa peneliti, maka penulis menambahkan sebuah metode dalam fase pengujian aplikasi yang telah dibuat, yaitu dengan menambahkan metode pengujian System Usability Scale dan User Experience Questionnaire yang berguna untuk mengetahui tingkat kebergunaan dan pengalaman pengguna terhadap aplikasi cleanstic mulai dari seberapa mudah difahaminya aplikasi ini sampai mudah digunakan atau tidaknya.

Dengan ditambahkannya metode System Usability Scale dan User Experience Questionnaire pada pengujian aplikasi cleanstic diharapkan lebih tepat dan akurat dalam menghasilkan aplikasi yang menjawab, memenuhi kebutuhan, memberikan kemudahan dan memberikan kenyamanan bagi pengguna.

Penelitian ini bertujuan sebagai sebuah inovasi untuk membuat solusi dari permasalahan sampah plastik sebagai upaya dalam mengedukasi masyarakat dan sebagai solusi dalam penanggulangan sampah plastik, yang mana rentang usia pengguna berada pada usia produktif yaitu 15 - 55 tahun. Aplikasi ini diharapkan dapat menjadi sebuah solusi dalam permasalahan tersebut khususnya bagi masyarakat umum.

\section{Metode Penelitian}

Dalam perancangan prototype aplikasi cleanstic, dilakukan berbagai macam proses yang disadur dari metode design thinking sebagai acuan, adapun prosesnya adalah sebagai berikut[5] :

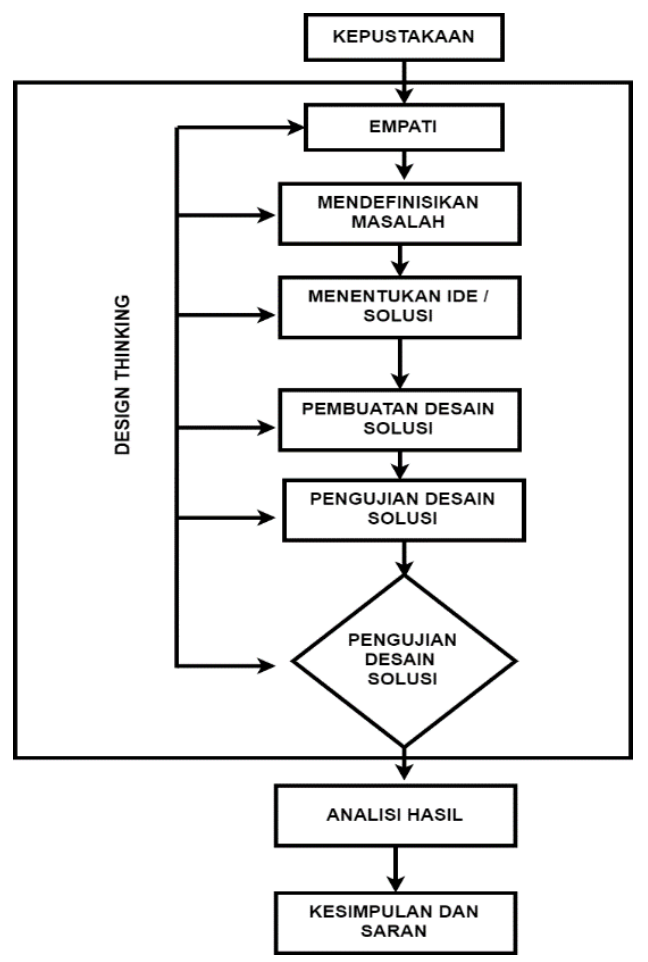

Gambar 1. Metode Penelitian
Diagram alir yang akan digunakan pada penelitian ini adalah seperti pada Gambar 1. Tahapan studi kepustakaan adalah proses dalam mencari sebuah referensi teori yang relevan dengan studi kasus atau permasalahan yang akan diangkat. Informasi yang dikumpulkan mengenai dampak dari penggunaan plastik, user experience, prototype, design thinking dan aplikasi. Referensi didapatkan dari buku acuan, artikel, jurnal ataupun pada situs yang berada diinternet.

\subsection{Tahapan Pengumpulan Data}

Digunakan beberapa metode yang dilakukan dalam fase pengumpulan data perancangan prototype aplikasi cleanstic, yaitu sebagai berikut:

\subsubsection{Studi Kepustakaan}

Studi kepustakaan adalah sebuah proses mencari sebuah referensi yang relevan dengan kasus ataupun permasalahan yang akan diangkat sebagai landasan dalam perancangan sebuah solusi. Referensi yang didapatkan berasal dari jurnal, buku dan melalui situssitus informasi yang berada di internet[6].

\subsubsection{Observasi Lapangan}

Observasi lapangan adalah teknik yang dilakukan langsung dengan melihat keadaan yang sebenar-benarnya terjadi dilapangan. Observasi ini juga bertujuan untuk memahami masalah yang dihadapi warga. Dalam kasus ini, observasi dilakukan pada warga lingkungan RT 10 RW 09 kelurahan pasar manggis.

\subsubsection{Survei}

Survei adalah sebuah proses untuk mengetahui siapa koresponden kita, keresahan mereka terhadap suatu masalah, serta untuk mengetahui masukan-masukan dari pernyataan mereka. Survei ini juga bertujuan untuk memahami masalah yang dihadapi oleh warga.

\subsection{Mendefinisikan Masalah}

Setelah melewati fase memahami masalah atau emphatize, dilakukan proses mendefinisikan masalah. Hasil dari proses mendefinisikan masalah ini disadur dari fase memahami masalah sebelumnya untuk kemudian dipilih beberapa topik masalah yang akan diangkat.

\subsection{Menentukan Ide atau Solusi}

Masalah yang telah diangkat pada fase sebelumnya kemudian dijadikan fokus untuk ditentukannya sebuah ide atau solusi pada tahap ini.

\subsection{Pembuatan Desain Solusi}

Setelah ide ataupun solusi telah ditentukan pada fase sebelumnya, selanjutnya adalah dilakukan sebuah pembuatan desain dari ide ataupun solusi tersebut. Platform yang digunakan untuk prototype adalah Android, pembuatan desain solusi dimulai dari proses pembuatan sebuah sketch, wireframe dan high-fidelity prototype. Perancangan prototype menggunakan software 
Figma dan Marvel[7].

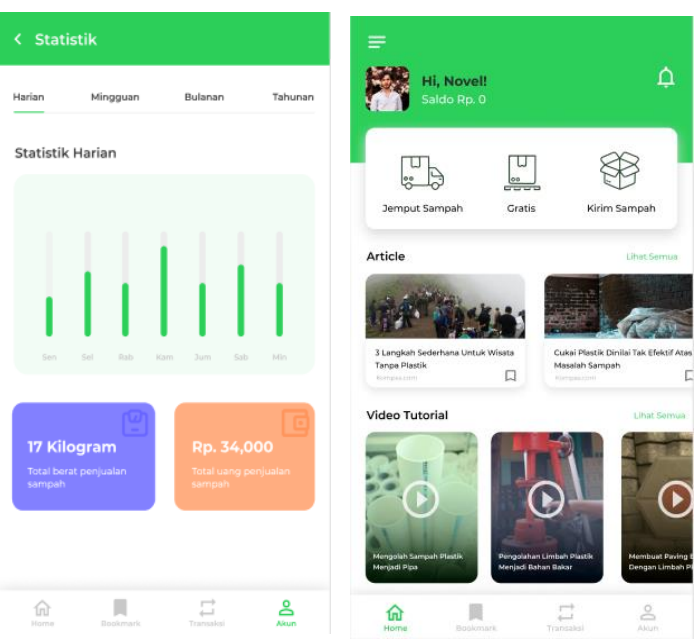

Gambar 2. User Interface Cleanstic

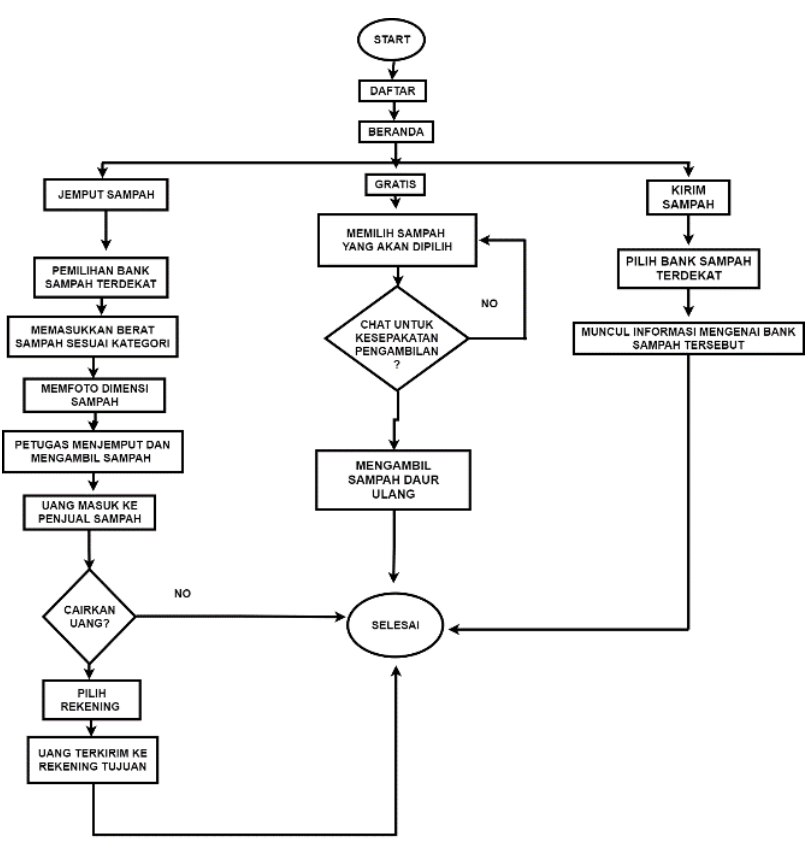

Gambar 3. Flowchart Proses Sistem

Proses sistem diawali dengan mendaftar, setelah mendaftar selanjutnya pengguna akan masuk ke tampilan beranda sistem untuk kemudian memilih fitur yang akan dipilih untuk digunakan pada sistem. Fitur pertama yang dipilih ialah jemput sampah, setelahnya muncul bank sampah atau pengepul terdekat pada sistem dari lokasi pengguna.

Kemudian pengguna memasukkan berat sampah yang akan dijual sesuai dengan kategori dan setelahnya memfoto sampah yang akan dijemput oleh petugas, setelahnya sampah diambil petugas dan uang hasil penjualan akan masuk ke sistem untuk kemudian dicairkan dengan cara melakukan transfer ke rekening yang dituju.

Kemudian pemilihan fitur gratis pada sistem, yang mana pada fitur ini pengguna dapat mengambil sampah yang telah pengguna lain posting untuk disumbangkan secara gratis dan boleh dimanfaatkan siapapun. Pengguna memilih sampah yang akan diambil dalam fitur ini, kemudian pengguna saling menentukan kesepakatan dengan penyumbang sampah perihal lokasi pengambilan dan setelahnya sampah diambil kemudian selesai.

Kemudian pemilihan fitur kirim sampah pada sistem, yang mana pada fitur ini pengguna dapat melihat perihal informasi bank sampah atau pengepul terdekat. Setelah pengguna memilih bank sampah yang akan dilihat informasinya, maka akan muncul informasi tersebut.

\subsection{Pengujian Desain Solusi}

Pengujian desain solusi dilakukan dengan memberikan beberapa tugas terkait dengan penggunaan prototype tersebut, pada fase ini kita dapat mengetahui bagaimana pengalaman pengguna ketika mencoba menggunakan prototype aplikasi cleanstic[8]. Apakah pengguna merasa kesulitan atau tidak menggunakan prototype aplikasi ini.

Pada fase ini juga dapat menentukan apakah desain solusi kita harus diperbaiki atau tidak, semua bergantung pada kemudahan pengguna dalam menyelesaikan tugas-tugas yang telah diberikan.

\subsection{Analisis Hasil}

Fase analisis hasil dilakukan untuk mengetahui apakah metriks-metriks yang ditentukan belum atau sudah tercapai. Proses analisis ini dicapai dengan menggunakan System Usability Scale dan User Experience Questionaire[9-10].

\subsection{Kesimpulan dan Saran}

Penulisan kesimpulan dan saran dilakukan ketika hasil dari ujicoba pengujian desain solusi dan hasil analisis telah sesuai dengan yang diharapkan. Isi kesimpulan berisi mengenai hasil analisis yang dilakukan pada fase pengujian desain solusi dan analisis hasil.

\section{Hasil dan Pembahasan}

\subsection{Analisis Kebutuhan Pengguna}

\subsection{Identifikasi Pengguna}

Hasil dari analisis yang telah diolah dari proses survei terhadap pengguna menghasilkan banyak keluhan yang dihadapi oleh pengguna terhadap masalah yang akan diangkat[11]. Hasil yang didapatkan dari proses survei yang dilakukan adalah banyak dari koresponden yang mengetahui akan hal-hal yang bisa dilakukan untuk 
mengurangi limbah plastik dan hal yang dapat dilakukan untuk mengolah limbah plastik.

Namun banyak koresponden yang tidak mengetahui bagaimana cara untuk mengolah limbah plastik tersebut agar bisa bermanfaat dan dapat menghasilkan.

\subsection{Identifikasi Karakteristik Pengguna}

Adapun karakteristik pengguna aplikasi cleanstic adalah sebagai berikut :

1. Semua masyarakat pengguna smartphone berbasis android

2. Aplikasi dapat dipakai oleh laki-laki maupun perempuan

3. Pengguna aplikasi minimal berusia 15 sampai dengan 55 tahun

\subsection{Identifikasi Kebutuhan Pengguna}

Identifikasi kebutuhan pengguna didapatkan melalui wawancara dan survei yang telah dilakukan pada tahapan sebelumnya, pada tahap ini diperoleh banyak sekali masukkan dari pengguna melalui wawancara dan survei online yang telah dilakukan. Tetapi dikarenakan keterbatasan waktu maka dipilihlah beberapa permasalahan atau kebutuhan pengguna.

\subsection{Persona}

Persona berisi tentang ringkasan informasi pengguna yang telah di research dengan metode wawancara survei yang telah dilakukan sebelumnya. Hasil survei yang telah didefinisikan permasalahannya, kemudian di rangkum menjadi sebuah persona yang berisi informasi imajinatif pengguna deskripsi, kesulitan pengguna dan kebutuhan atau keinginan yang pengguna harapankan.
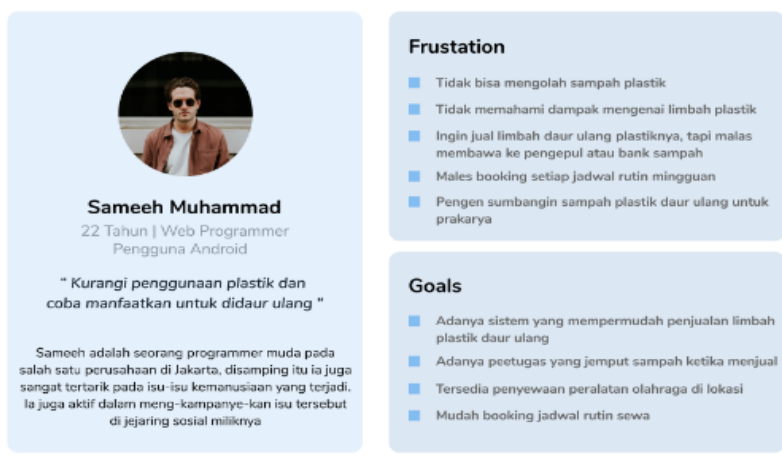

Gambar 4. Persona

\subsection{Identifikasi Tujuan Produk}

Tujuan dari perancangan prototype aplikasi cleanstic adalah sebagai sebuah penawaran sebuah solusi dalam mengedukasi masyarakat dalam menanggulangi sampah plastik dan juga menjembatani masyarakat dengan bank sampah ataupun pengepul sampah agar sampah plastik daur ulang mereka menjadi bernilai ekonomis.

Adapun tujuan yang dapat pengguna capai melalui aplikasi cleanstic adalah sebagai berikut :

1. Sampah plastik daur ulang yang akan dijual dapat dijemput dilokasi penjual

2. Dapat mendonasikan sampah plastik daur ulang agar dapat dimanfaatkan oranglain

3. Dapat melihat informasi mengenai lokasi pengepul ataupun bank sampah terdekat

4. Masyarakat bisa mendapat edukasi mengenai pengolahan dan pemanfaatan sampah plastik

\subsection{Identifikasi Lingkungan Sistem}

Dalam identifikasi lingkungan sistem berisi mengenai spesifikasi mengenai perangkat keras, perangkat lunak dan juga mengenai kelengkapan lain yang harus dipenuhi sebagai syarat untuk menggunakan aplikasi cleanstic. Identifikasi lingkungan sistem dijelaskan pada Tabel 1.

Tabel 1. Lingkungan Sistem

\begin{tabular}{llll}
\hline No & \multicolumn{3}{c}{ Karakteristik Sistem } \\
\hline 1 & Perangkat & \multicolumn{2}{l}{$\begin{array}{l}\text { Smartphone android dengan } \\
\text { minimal memori 1Gb }\end{array}$} \\
\hline 2 & Keras & Perangkat & $\begin{array}{l}\text { Sistem operasi android } \\
\text { minimal versi 4.4 } \\
\text { Aplikasi cleanstic }\end{array}$ \\
& Lunak & $\begin{array}{l}\text { Menggunakan internet } \\
\text { Mengaktifkan gps } \\
3\end{array}$ & Kelengkapan \\
& Lainnya & Mengaktifkan akses kamera \\
\end{tabular}

\section{Perancangan Desain Solusi}

\subsection{Information Architecture}

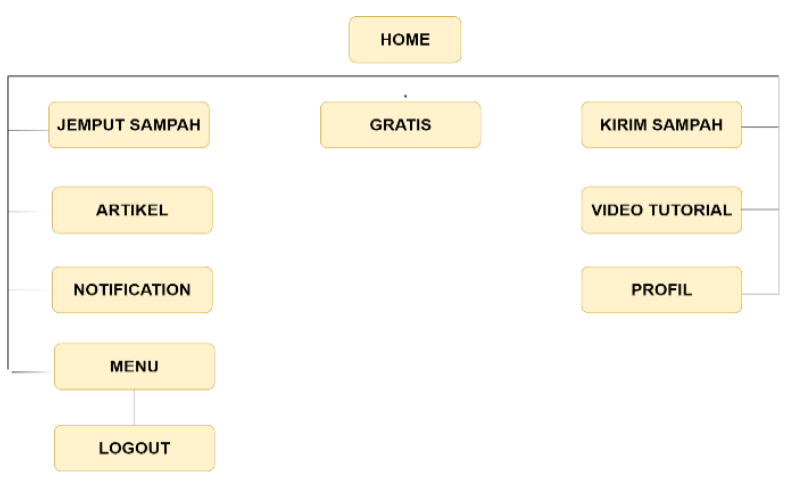

Gambar 5. Information Architecture

Pada gambar 5 terdapat information architecture dari aplikasi cleanstic, pada gambar diatas model dari information architecture berbentuk sebuah hirarki. Informasi yang disajikan pada gambar 5 adalah menu utama, yang mana pengguna bisa mengkases fungsifungsi atau fitur tersebut melalui menu utama.

\subsection{Wireframe}

Wireframe merupakan sebuah gambaran kerangka atau biasanya disebut low-fidelity sebuah desain aplikasi yang berfungsi sebagai gambaran tata letak konten- 
konten yang akan didesain menjadi sebuah Mock Up yang memiliki tampilan lebih detail dengan penambahkan unsur warna, icon dan typography.
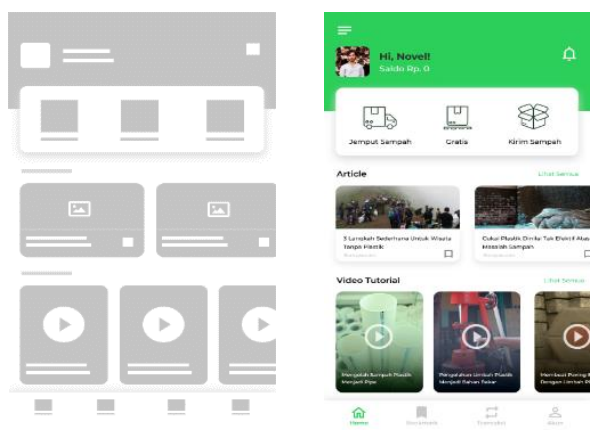

Gambar 6. Wireframe dan Mockup Halaman Utama

\subsection{Prototype}

Berdasarkan beberapa tahapan desain hingga menghasilkan sebuah mock up, selanjutnya dirancanglah sebuah prototype agar sebuah desain aplikasi agar lebih interaktif ketika diujicoba dan digunakan kepada pengguna nantinya. Interaksi yang tambahkan pada prototype ini seperti swipe dan click. Software yang digunakan Pada perancangan prototype desain aplikasi cleanstic ini adalah Figma dan Marvel App.

\section{Evaluasi Desain Solusi}

\subsection{Hasil Usability Testing}

Kuisioner SUS diisi oleh pengguna ketika selesai menggunakan prototype aplikasi cleanstic, berdasarkan hasil usability testing yang dilakukan kepada pengguna dengan menggunakan System Usability Scale ( SUS ). hasil yang didapatkan adalah sebagai berikut :

Tabel 2. Hasil SUS

\begin{tabular}{cccc}
\hline No. & Parameter & P1 & P2 \\
\hline $\mathbf{1}$ & Learnability & 58.3 & 62.5 \\
\hline $\mathbf{2}$ & Usability & 80.2 & 82.8 \\
\hline $\mathbf{3}$ & SUS Score & 75.8 & 78.8 \\
\hline
\end{tabular}

Adapun hasil dari SUS score pengujian pertama, menunjukkan nilai 75.8 yang mana nilai tersebut jika dilihat pada table 2 merupakan termasuk grade C[12-13]. Artinya hasil pengujian sudah baik, karena termasuk grade $\mathrm{C}$ yang termasuk kategori good.

Setelahnya diujicobakan kembali pada pengujian kedua, dan menunjukkan nilai 78.8 yang mana nilai tersebut termasuk grade $\mathrm{C}$, yang artinya hasil pengujian kedua juga menunjukkan hasil yang baik dan termasuk kategori good.

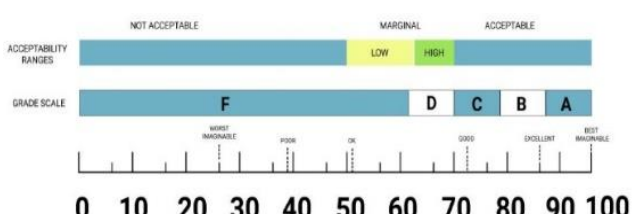

Gambar 7. Penilaian SUS Score

\subsection{Pengukuran $U X$ dengan User Experience Questionnaire}

Berdasarkan pengujian yang telah dilakukan menggunakan User Experience Questionnaire, maka didapatkan hasil rata-rata skala seperti pada gambar 6[14-15]. Adapun nilai rata-rata skala yang dihasilkan adalah Attractiveness 2.197, Perspicuity 2.275, Efficiency 2.150, Dependabillity 2.050, Stimulation 2.383 dan Novelty sebesar 2.089

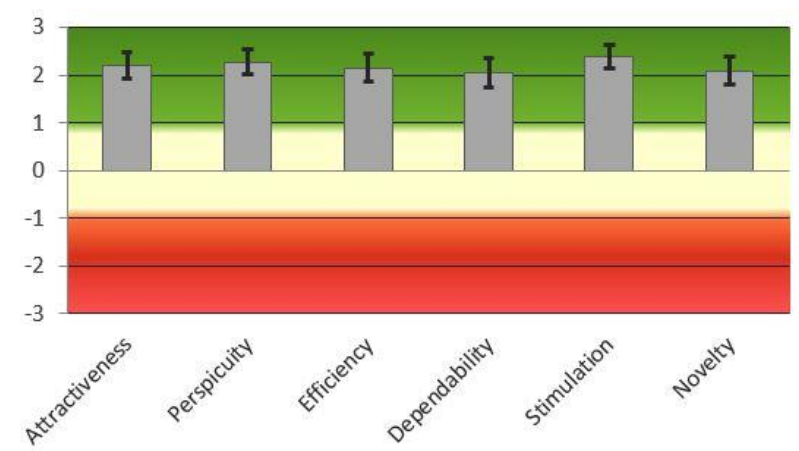

Gambar 8. Rata-Rata Skala Pengujian $U E Q$

Dari pengujian diatas menunjukkan bahwa perancangan prototype yang dilakukan telah menghasilkan kesan yang sangat baik pada prototype aplikasi cleanstic.

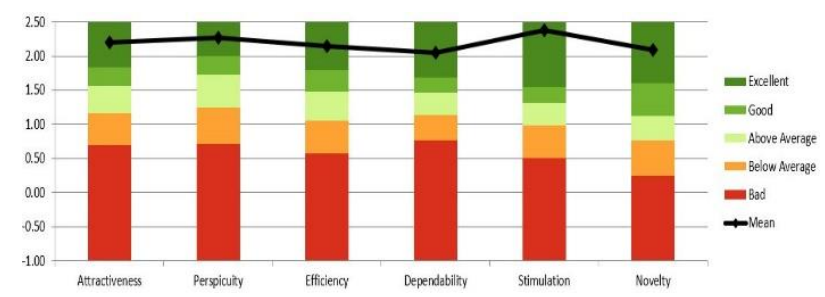

Gambar 9. Hasil Benchmark Desain Solusi

Berdasarkan hasil benchmark yang telah diperoleh seperti yang terlihat pada gambar 7 diatas. Terlihat hasil yang sangat baik pula dari pengujian desain solusi cleanstic yang telah diujicobakan, semua aspek mulai dari tingkat Attractiveness, Perspicuity, Efficiency, Dependabillity, Stimulation dan Novelty mendapatkan nilai yang sama, yaitu excellent.

\section{Daftar Pustaka}

[1] S. Amalina, F. Wahid, V. Satriadi, F. S. Farhani, and N. Setiani, "Rancang Purwarupa Aplikasi UniBook Menggunakan Metode Pendekatan Design Thinking," Semin. Nas. Apl. Teknol. Inf., pp. 50-55, 2017.

[2] A. A. Razi, I. R. Mutiaz, and P. Setiawan, 
"Penerapan Metode Design Thinking Pada Model Perancangan Ui/Ux Aplikasi Penanganan Laporan Kehilangan Dan Temuan Barang Tercecer," Desain Komun. Vis. Manaj. Desain dan Periklanan, vol. 3, no. 02, p. 75, 2018.

[3] L. Fanani, "Penerapan User-Centered Design dalam Pengembangan Aplikasi Pencarian Gedung Berbasis Android," Cybernetics, vol. 2, no. 02 , p. $225,2018$.

[4] Y. Firantoko, H. Tolle, and H. M. Az-zahra, "Perancangan User Experience Dengan Menggunakan Metode Human Centered Design Untuk Aplikasi Info Calon Anggota Legislatif 2019," J. Pengemb. Teknol. Inf. dan Ilmu Komput., vol. 3, no. 3, pp. 2798-2806, 2019.

[5] J. Matthews and C. Wrigley, "Design and Design Thinking in Business and Management Higher Education," J. Learn. Des., vol. 10, no. 1, p. 41, 2017.

[6] A. N. Aniesiyah, H. Tolle, H. M. Az-Zahra, "Perancangan User Experience Aplikasi Pelaporan Keluhan Masyarakat Menggunakan Metode Human-Centered Design," JPTIIK., vol. 2, no. 11, pp. 5503-5511, November 2018.

[7] H. N. Fauzi, V. Effendy, and D. Junaedi, "User Interface Model of Jigsaw Puzzle Based on User Experience on Early Children with Children Centered Design Methods," vol. 119, no. 15, pp. 2989-2996, 2018.

[8] F. Muhammad, R. A. Nugroho, and D. Turianto $\mathrm{N}$, "Analisis User Experience Untuk Tingkat Keterpilihan Smartphone Android," Kumpul. J. Ilmu Komput., vol. 04, no. 01, pp. 82-91, 2016.

[9] M. Schrepp, A. Hinderks, and J. Thomaschewski, "Construction of a Benchmark for the User Experience Questionnaire (UEQ)," Int. J. Interact. Multimed. Artif. Intell., vol. 4, no. 4, p. 40, 2017.

[10] A. Hinderks, M. Schrepp, J. Thomaschewski "A Benchmark for the Short Version of the User Experience Questionnaire," WEBIST., pp. 373377, 2018.

[11] E. Susilo, F. D. Wijaya, and R. Hartanto, "Perancangan dan Evaluasi User Interface Aplikasi Smart Grid Berbasis Mobile Application," J. Nas. Tek. Elektro dan Teknol. Inf., vol. 7, no. 2, pp. 150-157, 2018.

[12] U. Ependi, F. Panjaitan, and H. Hutrianto, "System Usability Scale Antarmuka Palembang Guide Sebagai Media Pendukung Asian Games XVIII," J. Inf. Syst. Eng. Bus. Intell., vol. 3, no. 2, p. 80, 2017.

[13] A. Bangor, T. Staff, P. Kortum, J. Miller, and T. Staff, "Determining what individual SUS scores mean: adding an adjective rating scale," Determ. what Individ. SUS scores mean adding an adjective Rat. scale, vol. 4, no. 3, pp. 114-123, 2009.

[14] S. V. Izabal, I. Aknuranda, and H. M. Az-zahra,
"Evaluasi dan Perbaikan User Experience Menggunakan User Experience Questionnaire ( UEQ ) dan Focus Group Discussion ( FGD ) pada Situs Web FILKOM Apps Mahasiswa Fakultas Ilmu Komputer Universitas Brawijaya," J. Pengemb. Teknol. Inf. dan Ilmu Komput. Univ. Brawijaya, vol. 2, no. 9, pp. 3224-3232, 2018.

[15] V. Intanny, I. Widiyastuti, M. Dolorosa, and K. Perdani, "Pengukuran Kebergunaan dan Pengalaman Pengguna Marketplace Jogjaplaza . id dengan Metode UEQ dan USE Questionnaire Measuring Usability and User Experience of The Marketplace of Jogjaplaza . id Using UEQ and USE Questionnaire," vol. 3, no. 2, pp. 117-126, 2018. 